\title{
Formar professores de línguas para incluir em contextos de diversidade excludente
}

\section{Educating language teachers for inclusion in contexts of excluding diversity}

Sueli Salles Fidalgo é professora adjunta do Curso de Letras da Universidade Federal de São Paulo (Unifesp). Possui Licenciatura em Letras - Português/Inglês pela Universidade Federal Fluminense (UFF), especialização em Tradução pela Universidade de São Paulo (USP), mestrado e doutorado em Linguística Aplicada e Estudos da Linguagem pela Pontifícia Universidade Católica de São Paulo (PUC-SP). Em 2009, concluiu o segundo período de pós-doutorado, pela PUC-SP, com foco na formação de professores para a inclusão de alunos com necessidades educativas especiais (NEE) e, em 2011,concluiu na Universidade Estadual de Campinas (Unicamp) outro pós-doutorado sobre o mesmo tema.

Contato: ssfidalgo@terra.com.br

\section{Resumo}

Inserido em um paradigma crítico (Freire, 1970); em uma visão de ensino-aprendizagem com foco na tríade conflito-negociação-transformação (Vygotsky, 1934; Bakhtin/Volochinov, 1929; Habermas, 2004); em uma visão de linguagem como "arena de conflito" (Bakhtin/ Volochinov, 1929) e em uma metodologia que vê a colaboração (Magalhães, 2007) que ocorre na zona de desenvolvimento proximal como instrumento por excelência para a modificação dos sentidos e significados que todos trazem para a sala de aula, este trabalho enfoca a dicotomia ex-/inclusão, discutindo-a pela perspectiva histórica da educação brasileira para demonstrar que uma escola prioritariamente excludente não se torna inclusiva por força da lei, mas pela formação de seus agentes. A pesquisa se realiza (1) por meio de reuniões de formação de professores que trabalham com alunos com necessidades especiais e (2) 
por meio de visitas da pesquisadora-formadora às escolas cujos professores participam deste trabalho para gravação e análise das aulas e das entrevistas. Além da pesquisadoraformadora, participam do trabalho professores de línguas de escolas públicas da Grande São Paulo e seus alunos com necessidades educativas especiais. Inicialmente, as reuniões tiveram como objetivo discutir os problemas que os educadores têm para garantir um espaço de inclusão; hoje, enfocamos o desenvolvimento de materiais para alunos incluídos, para que estes não fiquem alheios às atividades escola. Encontrar uma ação que possa ser realizada pelo aluno com necessidades educativas especiais como membro participante da atividade social realizada é permitir que esse aluno seja também agente de seu desenvolvimento porque permite que ele crie quem ele é ao ser quem ele não é (Vygotsky, 1934).

Palavras-chave: necessidades educativas especiais; formação de professores; colaboração; dicotomia exclusão/ inclusão.

\section{Abstract}

Based on a critical paradigm (Freire, 1970); on a teachinglearning view which focuses on the conflict-negotiationtransformation triad (Vygotsky, 1934; Bakhtin/Volochinov, 1929; Habermas, 2004); on a view of language as a zone of conflict (Bakhtin/Volochinov, 1929) and on a methodological organization that sees collaboration (Magalhães, 2007) which originally takes place within the zone of proximal development - as tools par excellence when it comes to the transformation of the senses and meanings that each individual brings to the classroom, this paper focuses on the ex-/inclusion dichotomy, discussing it from the historical perspective of Brazilian educational system so as to show that a school system that is excluding in nature and formation does not become inclusive by order of a new law, but by the education of its agents. The research is carried out by means of (1) teacher education meetings with participants whose students have special educational needs (SEN) and (2) visits from the researcher-teacher educator to schools whose teachers take part in this project, so as to record and analyze their lessons and interviews. Besides the teacher-educator, other participants are: language teachers 
from State Public Schools in the outskirts of the city of Sao Paulo and their SEN students. Initially, meetings were held with a view to discussing the problems that the educators had when attempting to guarantee a locus o inclusion in their schools. Today, we focus on the development of material for SEN students include in these regular schools so as to prevent them from being left aside from the general classroom task while "included" in the classroom. Finding an action that may be carried out by the SEN student as an active participant of the general social activity that their peers are also involved in is allowing this student to also become an agent of his/her development because it allows him/her to creatively become who s/he cannot Be at this very moment (Vygotsky, 1934).

Keywords: special educational needs; teacher education; collaboration; exclusion/inclusion dichotomy.

Este trabalho tem como preocupação central a percepção de que mesmo os atuais egressos de cursos de licenciatura têm recebido pouca ou nenhuma formação para o trabalho com a diversidade em sala de aula, aqui incluídas as necessidades especiais, mas também incluídos outros fatores de exclusão social que já estavam presentes em nossas escolas antes da LDB 9394/96, que defende a inclusão escolar. 0 texto se dividirá em três partes, a saber: (1) a metodologia de ação e de pesquisa; (2) uma discussão sobre exclusão e inclusão historicamente colocadas; (3) uma discussão sobre o problema da formação do professor.

Além disso, é importante lembrar que falo do lugar social de linguista aplicada, o que, para mim, como para muitos linguistas aplicados (Magalhães; Fidalgo, 2010, 2008; Liberali, 2011), significa assumir um papel que questiona a linguagem utilizada muitas vezes de forma irrefletida. Significa também pensar na linguagem como organizadora do pensamento, de forma crítico-reflexiva. Essa visão tira a linguagem de uma posição tida como apolítica e faz de seus usuários agentes de mudança, responsáveis por suas ações e pontos de vista, capazes de investigar suas ações com o objetivo de transformar as situações de iniquidade e opressão que vivenciam. Essa é a premissa por trás dos trabalhos de formação de educadores assumida neste trabalho investigativo que será desenvolvida na seção de formação. 


\section{Questões metodológicas}

As questões metodológicas da investigação realizada e aqui relatada têm base sócio-histórico-cultural. Mais especificamente, é no conceito vygotskyano de zona proximal do desenvolvimento (ZPD) que me embaso. Vygotsky (1934) deixa claro que a contínua organização e reorganização de formas rudimentares e de formas desenvolvidas de fala, por meio de atividade partilhada, cria a ZPD, ao mesmo tempo em que atua nela. Ainda assim, para que haja uma atividade que, de fato, possa ser chamada de transformadora, o formador de professores precisa criar situações concretas de aprendizagem-desenvolvimento que permitam que todos os participantes se envolvam em negociações teórico-práticas que possam promover a compreensão, assim como o questionamento tanto dos significados aparentemente partilhados que as ações/ palavras demonstram, como dos interesses que sustentam tais significados. Dessa forma, o que é, na realidade, internalizado pelos participantes é aquilo que vai sendo construído pelo grupo em relação às teorias e às práticas, no momento, por exemplo, das discussões sobre as ações de sala de aula ou de elaboração de material. As teorias não são, portanto, introduzidas de forma global (e por isso mesmo, estabelecidas a priori) -dissociadas das teorias e práticas locais (Mignolo, 2003).

0 foco da formação está, nesse caso, no social (e na colaboração, ou na negociação de sentidos e significados) e não na construção individual de conhecimento (Magalhães, 2011). Em pesquisas que se delineiam nessa perspectiva, o pesquisador precisa tomar um cuidado extra para que, estando o foco na coletividade e o objetivo na transformação do status quo, não fique a impressão de que essa transformação se daria por meio da rejeição das opiniões de um grupo em favor das de outro (principalmente, no que diz respeito às relações de poder que, frequentemente, se estabelecem entre pesquisador(es) e os demais participantes). Em outras palavras, é preciso tomar cuidado para que as opiniões dos mais fortes não sejam automaticamente tomadas como opiniões fortes (Bauman, 1997).

Os diálogos precisam, portanto, ser definidos pelo cuidado com que é necessário ouvir os demais com uma atitude responsiva (Bakhtin/Volochinov, 1929) que nos permita pedir esclarecimento, discordar, questionar, sem, no entanto, impor ideias. É um contexto que vai se organizando enquanto a atividade de formação também se organiza. Não cabe aqui qualquer medida de neutralidade - seja relativa ao método de geração de dados, seja em termos de pré-organização do espaço de formação. Todos os 
participantes precisam se sentir em posição confortável para trazer o seu ponto de vista, sabendo que este servirá para a construção do conhecimento. Todos têm a oportunidade - e até a obrigação - de questionar as demais falas quando não concordam com elas ou não as compreendem; e isso deve ser feito sem que qualquer um se sinta ameaçado. É assim que um lócus colaborativo que promova a coconstrução (ou correconstrução) de práticas é definido (Magalhães, 2007; Magalhães e Fidalgo, 2010).

Esse processo de construção conjunta de novos significados e teorias, papéis e ações, se dá no espaço chamado de ZPD - espaço no qual velhos significados se confrontam com novos conceitos por meio de (auto)avaliações críticas do que cada um pensa acerca do seu trabalho.

Portanto, a metodologia colaborativa - aqui utilizada - não deve implicar na transformação de um grupo por outro e sim na partilha de conhecimento, responsabilidade e transformação.

No que diz respeito à análise de dados, neste trabalho, utilizo a teoria de funcionamento dos discursos tal como discutida por Bronckart e Machado (2004), em sua intersecção com os pilares sócio-histórico-culturais que sustentam o interacionismo sociodiscursivo. Busco, portanto, nos dados coletados, evidências da linguagem da inclusão ou exclusão em documentos oficiais e nas falas dos educadores. Dos conceitos discutidos por Bronckart e Machado (2004), utilizarei, principalmente, os seguintes:

- Conteúdo temático (na fala dos professores e dos pesquisadores) - para analisar os sentidos e significados (Vygotsky, 1930, 1934; Leontiev, 1978) de ensinoaprendizagem e de ex-/inclusão veiculados na escola (e "para" a escola) antes e depois do início do trabalho de formação. Também será utilizado para a análise da linguagem impressa nos documentos oficiais. Aqui estão incluídas, portanto, as escolhas lexicais feitas.

- A análise das modalizações (Bronckart; Machado, 2004) que, de certa forma, também revelam os sentidos (valores) atribuídos a situações. As modalizações consideradas aqui serão:

- valor deôntico - com metaverbos tais como dever, ser preciso etc.;

- valor pragmático - com metaverbos tais como querer, tentar, buscar etc.; 
- valor psicológico - com metaverbos tais como pensar, acreditar etc.;

- valor epistêmico - com metaverbos tais como ser verdade, poder etc.;

- valor apreciativo - com metaverbos tais como gostar, apreciar etc.

Além desses conceitos, que são utilizados ao longo do texto de forma a intercalar análise, teoria e descrição do trabalho realizado, também utilizo os conceitos de discurso interditado e discurso autorizado (Foucault, 1970) - encontrados nos dados por meio dos verbos achar e saber. Para Foucault, a interdição é um tipo de exclusão, embora o autor a discuta, principalmente, pelo aspecto do poder falar e não do saber falar, quando afirma que "sabe-se bem que não se tem o direito de dizer tudo, que não se pode falar de tudo em qualquer circunstância, que qualquer um, enfim, não pode falar de qualquer coisa (p. 9)".

Tendo esclarecido os procedimentos metodológicos utilizados no presente trabalho, discuto, a seguir, o conceito de inclusão, em sua interface com o de exclusão.

\section{A dicotomia exclusão-inclusão historicamente colocada}

É preciso lembrar que, historicamente, nossas escolas parecem ter sido formadas mais pela exclusão do que pela inclusão, o que pode fazer com que a prática da inclusão seja um desafio ainda maior até pelos espaços e pela arquitetura escolares. Para nos certificarmos dessa formação excludente, basta que olhemos as constituições e as LDBs anteriores a 1996. Um exemplo seria, na Constituição Brasileira de 1934, o artigo 138, alínea b, que diz caber "à União, aos Estados e aos Municípios, nos termos das leis respectivas: (...) estimular a educação eugênica" (meu grifo). No mesmo artigo, é possível verificar que se queria "higienizar" a sociedade do que era considerado "anormalidade". Vê-se, por exemplo, uma referência ao cuidado da União em relação à "higiene social" (artigo 138, alínea f) e à "higiene mental" (artigo 138, alínea g). 0 que seriam higiene mental e social?

Textos e documentos do período em que essa constituição foi elaborada demonstram que essa era, sem dúvida, uma época em que alguns pesquisadores buscavam provar a inferioridade dos índios e negros por meio da avaliação de sua constituição física, do 
tamanho de seu crânio, dentre outros fatores. Patto (1999, p.114), discutindo a formação da sociedade brasileira, lembra que "os eruditos brasileiros" do início do século XX,

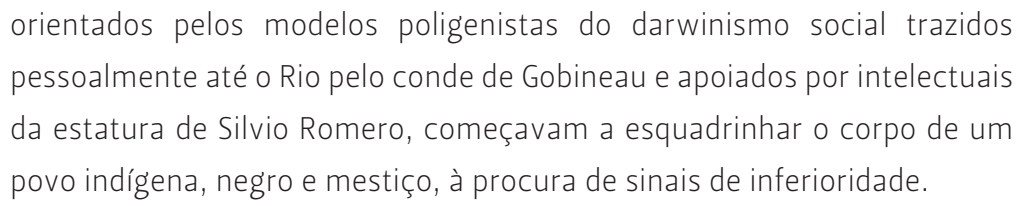

Assim, nossos intelectuais seguiam os franceses que, segundo Bisseret (1978, p. 42) defendiam que deveríamos, sim, ensinar a todos, mas também deveríamos atentar para as diferenças entre os filhos da burguesia e os demais, via de regra, "inferiores". Se o povo seria educado nas escolas públicas (por exemplo), a burguesia, "cuidando da distinção", deveria utilizar "um sistema de ensino primário paralelo e pago". Embora não me coloque contrária à escola paga, a distinção à qual se deveria cuidar me parece um indício da escola eugênica que se formava desde o início da República Velha - um indício, portanto, de educação excludente.

Os conceitos eugênicos de constituição hereditária, biológica, que defendiam a importância de multiplicar a raça de melhor inteligência foram vastamente documentados em textos do início do século XX, no início do Brasil republicano. Um exemplo seria Domingues (1929):

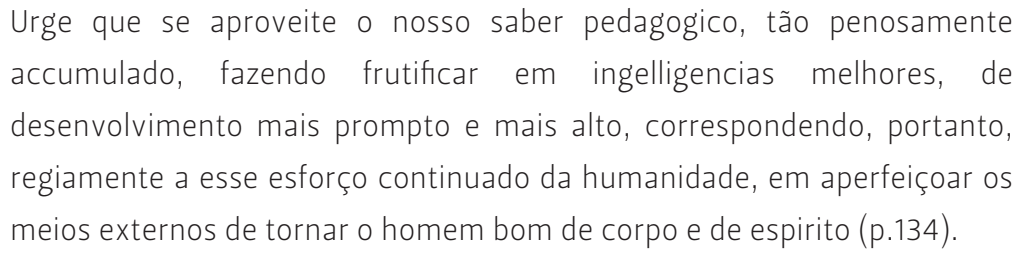

No Brasil que, na época, iniciava a formação de seu sistema escolar, multiplicaram-se textos que defendiam, por um lado, a reprodução "das familias eugenicas" (Domingues, 1929, p.137) e, por outro, "o aperfeiçoamento constante dos methodos de educação, de educação social do homem, afim de que os bons genotypos (das familias eugenicas)" encontrassem "um ambiente que" orientasse e conduzisse "seu desenvolvimento do modo mais efficiente possível" (ibid).

A mesma atitude de eugenia se faz presente na Constituição de 1937, quando, no artigo 129, encontramos o seguinte:

o ensino pré-vocacional profissional destinado às classes menos favorecidas é, em matéria de educação, o primeiro dever de Estado. (...) 
É dever das indústrias e dos sindicatos econômicos criar, na esfera da sua especialidade, escolas de aprendizes, destinadas aos filhos de seus operários ou de seus associados (meus grifos).

Assim, com uma escola destinada "às classes menos favorecidas" e outra para os que possuem "recursos necessários à educação...", fomos formando nossa escola excludente. Como discutido por Habermas (2004, p. 69), o princípio de eugenia biológica - "cuja meta era intervir na reprodução das populações" (Schwarcz, 1993, p. 60) - pode ter seu contraponto em uma eugenia ambiental, como no caso de nossas instituições escolares.

Se, por um lado, havia a escola classista (e racista), por outro, podemos ver que essa também era a época da abertura de instituições voltadas ao atendimento de crianças com necessidades especiais - a começar pela fundação do Imperial Instituto dos Meninos Cegos, em 1854, por D. Pedro II e, mais tarde, a fundação do Imperial Instituto de Surdos-Mudos, em 1857. A fundação desses espaços constituía o que Sassaki (2003) chamou de período de segregação institucional em nosso histórico de ex/ inclusão.

As crianças com necessidades especiais devido a deficiências mentais teriam que esperar um pouco mais por um espaço educacional já que as deficiências intelectuais eram tidas como resultado da miscigenação de raças. Dessa forma, os que tinham deficiências mentais eram incluídos em instituições cujos objetivos eram tratamento e prevenção e, é claro, o estudo. Não havia preocupação educativa nesse caso. São Paulo, por exemplo, teve sua primeira escola para alunos com deficiências intelectuais criada só na década de 30 do século passado. Ainda assim, a exclusão que até hoje permeia as práticas que vislumbram possibilidades de inclusão estava fortemente presente, até mesmo no nome pelo qual se referiam a essa escola: "escola de anormais".

A história nos mostra que as escolhas lexicais feitas para nos referirmos aos que têm necessidades especiais estão permeadas de concepções preconceituosas. Temos o Serviço de Higiene e Educação Sanitária Escolar, da década de 1930, a quem caberia selecionar os alunos para as diferentes escolas de educação especial; a Associação de Assistência à Criança Defeituosa, criada em 1950; o Setor de Educação de Mongoloides, criado em 1963 (Mazzotta, 1995).

A língua portuguesa em si está repleta de termos excludentes. Sassaki (2003, p.1) nos lembra que o Decreto Federal $n^{\circ} .60 .501 / 67$ 
chamava os que tinham necessidades especiais de "inválidos" - ou seja, indivíduos sem valor. Os jornais, as instituições etc., referiam-se aos "inválidos", aos "incapacitados", como nos exemplos citados por Sassaki (ibid):

1. "inválido pode voltar" (Folha de S. Paulo, 20/7/82).

2. "Os cegos e o inválido" (IstoÉ, 7/7/99).

3. "Derivativo para incapacitados" (Shopping News, Coluna Radioamadorismo, 1973).

4. "Escolas para crianças incapazes" (Shopping News, 13/12/64).

5. "Crianças defeituosas na Grã-Bretanha tem educação especial" (Shopping News, 31/8/65).

Hoje, com a divulgação da ideia de direitos iguais para todos, mas sem uma infraestrutura que ao menos desafie a formação da escola em nosso país, sem formação para os professores, sem condições físicas na maioria das escolas, sem ao menos profissionais que possam identificar, em cada escola, qual a necessidade apresentada pela criança, podemos dizer, como Habermas (2004, p. 68), que temos uma "nova eugenia liberal". Para esse autor, "enquanto eugenistas antiquados e autoritários procurariam produzir cidadãos a partir de um único molde central projetado, a marca distintiva da nova eugenia liberal é a neutralidade do Estado" que deixa a critério dos pais a decisão sobre o aperfeiçoamento educacional que os filhos deverão receber, isentando-se, portanto, de responsabilidades pela divulgação de slogans de "direitos iguais a todos". Alguns pais conhecem as reformas educacionais, as políticas públicas e os seus direitos, outros, apenas levam os filhos para a escola mais próxima de sua casa ainda que não saibam como esta poderá ajudá-los.

É essa a premissa básica deste trabalho. Para mim, se não houve, em nossa história, uma preocupação com a escola inclusiva, para implementá-la, após séculos de exclusão, é preciso um esforço preparatório que inclua a formação para todos os profissionais da escola, a (in)formação para os pais e a sociedade em geral, a abertura da escola para os pais que conhecem melhor o filho e sua necessidade especial, a adaptação física (incluindo equipamentos) da escola, dentre outros fatores. No entanto, o que vemos é uma adaptação a reboque, uma formação que pode ou não surgir depois que o professor já recebeu o aluno com determinada necessidade - e, às vezes, até já o passou adiante, como confirma as falas de uma professora (embora o tema de formação seja mais discutido posteriormente). 
Quadro 1 - Questões de falta de formação: conversa com educadora'

(...)

C64: Elas tão chegando, não, na realidade, a LDB entrou em 96, né? então, mais ou menos desde 96, quando saiu a LDB, elas já estavam chegando.

S62: mais de 10 anos.

C65: É. Tem criança que não só tá chegando como já foi embora. E foi embora em que condições? Entendeu?

C29: Então, o professor teve uma formação pra cuidar do aluno que é inteligente, que é ... que levanta a mão todas as vezes que ele pergunta pra poder responder e pronto. 0 aluno que desvia desse padrão, eu acho que o professor não tá preparado pra trabalhar com ele. E desvia em qualquer nível, né? Nesse nível físico, mental, visual, e mesmo o aluno indisciplinado. Aquele aluno que não quer ler, que não presta atenção. Eu acho que ele tá preparado praquele aluno padrão. 0 que saiu fora desse padrão, já era. Pra ele, é problema e ele não sabe resolver e ele não tem... é ... não existe no Estado nenhuma assessoria pra isso.

S34: então, de repente, você põe essas crianças numa escola regular e fala pro professor

C36: "SE vira!" Então, é assustador mesmo. E então, aí, as pessoas não sabem lidar. E daí, o que elas fazem? Ou elas entram em conflito consigo mesmas e ficam naquela guerra eterna do "eu não sei o que fazer". Ficam tentando várias coisas e não chegam a lugar nenhum...

Como se pode ver nos excertos, não há formação de professor e, sem ela, este não sabe o que fazer. Isso é enfatizado pelo uso do verbo saber em situação de discurso autorizado, ou seja, a educadora, nesse caso, tem certeza de que o professor não sabe, por isso, usa o discurso autorizado, sente-se autorizada a falar a respeito de uma situação que conhece. Em apenas um momento, utiliza "acho que ele tá preparado para aquele aluno padrão" único momento de discurso interditado, ou talvez de discurso em que ela não quer assumir essa certeza. A certeza do "não sabe", no entanto, ecoa com força no discurso da professora. É inegável que para ela, há algo de errado.

As dicotomias ex-/inclusão no Brasil nos levam a pensar em um conceito discutido por Alencar (2001, p.52): o conceito de ninguendade. Isso pode ser verificado em duas instâncias legais: (1) em nossa primeira LDB, a Lei 4024/61, na qual não há

1. $S=$ Sueli, pesquisadora; $C=$ professora de línguas participante do projeto. 
qualquer seção específica (Saviani, 1997) à educação de crianças com necessidades especiais, embora o projeto de Lei de Carlos Lacerda, em 1955 (que veio a ser aprovado como a LDB de 61), já tivesse mencionado a "Educação de Excepcionais" (Título XVII Saviani, 1997, p.17) - o que indica, portanto, que de alguma forma, o assunto já fora pensado; (2) nas constituições que tratam de exclusão social de modo mais abrangente, como a assistência ao que está em situação de necessidade, mas sem especificação do tipo de necessidade ou a maneira como (por meio de que órgãos) essa assistência será oferecida.

Dessa forma, discutem que cabe ao Estado, por exemplo: "assegurar amparo aos desvalidos, criando serviços especializados e animando os serviços sociais, cuja orientação procurarão coordenar" (Constituição de 1934, artigo 138, alínea a). Ou, ainda, que cabe ao sistema de ensino ter "obrigatoriamente, serviços de assistência educacional que assegurem aos alunos necessitados condições de eficiência escolar" (Constituição de 1967, artigo 169, parágrafo $2^{\circ}$ ).

Note-se que o próprio termo "eficiência escolar" coloca no aluno a culpa por sua incapacidade de atingir o que fora $a$ priori determinado como legítimo para cada nível. Em outras palavras, "tendo as mesmas oportunidades", o aluno que não atinge os mesmos níveis é incapaz. Se ele for identificado como "necessitado", então receberá assistência educacional.

A ideia de ninguendade - de não ver propriamente, de tornar invisíveis determinados indivíduos, de não ver quem eles realmente são, que culturas trazem para a partilha social, o que podem ensinar e o que gostariam de aprender - está bastante presente em nossa sociedade e, como não poderia deixar de ser, está firmemente presente em nossas escolas, como o exemplo a seguir demonstra. Nele, uma professora (que também é assistente técnico-pedagógica) descreve um exemplo extremo de ninguendade: um aluno está inserido na sala, mas não teria como estar incluído, uma vez que tem múltiplas deficiências e está em uma maca. 
Quadro 2 - Construindo a ninguendade

Ca34: (...) E dentro dessa instituição funciona uma Escola Estadual, tá? Então os alunos frequentam essa Escola Estadual, mas vivem na instituição. Ali, você tem Múltiplas Deficiências, você tem aluno, inclusive, em maca, tá?

S32: Como a inclusão acontece nesse caso?

Ca35: [silêncio! Suspiro! Riso!]

S33: Desculpe-me por perguntar.

Ca36: Não! tudo bem. É difícil. Não acontece.

Para Gentili (2001, p.30):

Em nossas sociedades fragmentadas [como, aliás, são as nossas escolas: microssociedades fragmentadas contidas em uma macrofragmentação], os excluídos devem se acostumar à exclusão. Os não excluídos também. Assim, a exclusão desaparece no silêncio dos que a sofrem e dos que a ignoram... ou a temem.

Além da formação e da aceitação de crianças com necessidades especiais, outro fator de exclusão dentro da inclusão escolar está na falta de adaptação predial e de equipamentos. Sassaki (2003, pp. 61-2) afirma que a integração, na prática, implica em uma de três possibilidades: (1) a admissão das pessoas deficientes no trabalho (ou na escola) desde que estas tenham as qualificações adequadas e "consigam utilizar os espaços físicos e os equipamentos (...) sem nenhuma modificação" - o que exclui mais da metade das pessoas com necessidades especiais; (2) a admissão de pessoas deficientes mediante "pequenas adaptações nos postos de trabalho [ou escolares], por motivos práticos e não necessariamente pela causa da integração social"; (3) a admissão de pessoas deficientes que são colocadas em "setores exclusivos, portanto segregativos, com ou sem modificações, de preferência afastados do contato com o público" (grifos meus).

Como se pode ver, assim como nas falas dos educadores, também a discussão fora dos contextos escolares indica que a inclusão de fato não existe - uma vez que ela pressupõe que o deficiente não precise, na realidade, de nenhuma adaptação espacial (a não ser "pequena") para ser incluído e/ou inserido em espaços que o isolam do restante do público. Em relação à adaptação, diversas são as falas dos educadores que indicam a necessidade de mudanças físicas nos prédios escolares para possibilitar a inclusão: 
Quadro 8 - Adaptação de espaço

C5: (...) Eles andam... tem alguns que andam se arrastando no chão dentro da sala. Então a sala tem que ter espaço, né? pra isso

e

Quadro 9 - Adaptação de prédios

C62: (...) Eu acho assim, o primeiro, o primeiro passo é que você tem que adaptar os prédios porque se não, não adianta. 0 que está sendo feito aqui colocando elevador, acho que é um... já é um passo, um avanço

0 uso do discurso interditado (com o verbo achar) no Quadro 4 indica que a professora não se sente capaz de solucionar esse problema, uma vez que não é ela quem deve decidir sobre as adaptações dos prédios. No entanto, as modalizações deônticas em ambos os quadros indicam a certeza de que a regra social é essa (é o que está na lei); logo, é o esperado: "tem que adaptar".

\section{A formação para a inclusão}

Em uma pesquisa crítica que tenha o foco na formação do educador, um dos resultados esperados é o de que este se torne (se ainda não for) investigador de sua própria prática, intelectual de sua ação em vez de alguém que reproduz práticas prescritas pela academia. Kincheloe (1993, pp. 205-206) ressalta que, no mundo pós-estruturalista, é preciso que a educação do professor seja orientada para: (1) a pesquisa, (2) a consciência do poder que exerce e a compreensão do contexto social no qual o trabalho ocorre; (3) um compromisso "em fazer o mundo", (4) a participação ativa no contexto, (5) uma autorreflexão e uma reflexão social críticas, (6) uma sensibilidade ao pluralismo e (7) o comprometimento com a ação, dentre outros. Nesse sentido, essa concepção de formação de professor se coaduna com o desenho da pesquisa em uma perspectiva colaborativa.

A concepção de Kincheloe apoia-se na pedagogia crítica defendida por Freire. Discutindo a concepção bancária de ensinoaprendizagem (que resulta - assim como é o resultado - de um currículo e formação de professor fragmentados), Freire (1970, p. 85) afirma que essa concepção "desenvolve uma ação apassivadora, coincide com o estado de "imersão" da consciência oprimida". 
Para Freire, não é a oposição de um discurso ao outro que promoverá a transformação social, mas a formação para a conscientização de sua condição subalterna. Em outras palavras: "o empenho (...) está em que os oprimidos tomem consciência de que, pelo fato mesmo de que estão sendo "hospedeiros" dos opressores, como seres duais, não estão podendo ser (1970, p. 86, grifo meu)".

Não bastaria, portanto, substituir a linguagem de um grupo social ou político por outro. A formação de professores não poderia ser pautada no ensino (por uns) e apropriação de práticas, técnicas ou mesmo conceitos (por outros). É preciso permitir que as linguagens em conflito possam ser compreendidas pelos agentes que, em última análise, as validam e utilizam - talvez inconscientemente. Caso contrário, estando na Linguística Aplicada, tenho o dever de ressaltar que tais agentes (ex.: os educadores) estariam a serviço da manutenção de uma linguagem cujos objetivos, muitas vezes, desconhecem porque não foram formados para ler nas entrelinhas, a "letra miúda" que traz os "efeitos colaterais". Ao mesmo tempo, seria obrigada a denunciar que a formação de professores estaria a serviço também da mesma manutenção - "fazendo comunicados" (Freire, 1970), mas não "comunicando".

Devo ressaltar, mais uma vez, que não questiono as decisões de inclusão senão pela forma atropelada e invertida em que esta se dá - sem formação para o profissional e sem as adaptações espaciais e curriculares necessárias, obrigando, portanto, (1) ao próprio aluno que se adapte aos espaços e aos currículos e aulas fragmentadas e fechadas como se articulam e (2) ao educador que se adapte também às novas exigências profissionais.

Como dizia Freire (1996, p. 22),

do ponto de vista dessa ideologia [a ideologia neoliberal que dita as regras sociais e escolares nos dias de hoje] só há uma saída para a prática educativa: adaptar o educando à realidade que não pode ser mudada. 0 que se precisa, por isso mesmo, é o treino técnico indispensável à adaptação do educando, à sua sobrevivência.

0 mesmo acontece com o professor que ainda é formado por uma concepção de treinamento da técnica sobre o conteúdo de sua disciplina, no que acaba por formar um ciclo vicioso da educação para e pela técnica que não resolve - sequer compreende - os problemas escolares. Muitas vezes, isso acaba resultando na manutenção dos "slogans dos opressores" nas bocas 
dos oprimidos, que os repetem, tornando-se opressores de outros, que também os repetirão sem perceber a quem servem.

Argumento aqui, que, se houver um caminho para que a formação do professor possa resultar em mudanças na escola, este se dará por meio dos conceitos de (1) colaboração e de (2) desnaturalização do invisível - sendo este muitas vezes atingido por meio da reflexão crítica e da apropriação de um arcabouço de argumentação. Essa combinação parece permitir que os educadores, em primeiro lugar, compreendam a linguagem que os mantém oprimidos; em segundo, sintam-se confiantes para mudar sua situação de oprimidos - sabendo como questionar e onde buscar ajuda e, em terceiro, mudem sua postura de opressores para colaboradores em relação a seus alunos.

É ainda Kincheloe (1993, p.13) que afirma que "as escolas da era pós-iluminista enfatizaram não a produção do conhecimento, mas a aprendizagem daquilo que já havia sido definido como conhecimento". Logo, estamos diante de um quadro de professores formados não para a produção do conhecimento, não para serem intelectuais de suas práticas, mas para buscarem nos livros, nos compêndios, na academia, de um modo geral, as soluções prontas para os problemas que enfrentam.

Assim foi a sua formação - fragmentada, com base em conteúdos prontos, "definidos como conhecimento". Não foi uma formação com o pressuposto de que "quem forma se forma e re-forma ao formar e quem é formado forma-se e forma ao ser formado" (Freire, 1996, p.25). Em sua formação acadêmica não havia espaços para a discussão de que, embora profissionais formados, precisariam ser constantemente re-formados - muitas vezes pelos próprios alunos, pais, comunidade, o que requer um enorme exercício de humildade.

Hoje, porém, temos tamanha diversidade nas escolas que nenhum compêndio acadêmico traria tantas respostas para tantos problemas que, inevitavelmente, surgem nos ambientes escolares, como demonstram os dados abaixo: 
Quadro 5 - Diversidade em sala de aula: falas de uma professora de escola pública

F4: (...)E eu tinha um certo receio, né? Assim, um pouco assim de medo.

(...) eu via uma menina, que ela vinha num carrinho de bebê, só que era um carrinho maior. Eu via o carrinho no corredor e às vezes, o pessoal empurrando. E eu tinha pavor... de enfrentar, né? Porque ninguém falou nada e eu sabia que eu ia pegar a classe dela. (...) E eu fiquei uns dias sem entrar naquela sala (...).

F6: Acho que deve ter sido 96 ou 97. (...) E, agora, teve outros... gente como cadeirante, né? Mas aí é a parte física, né? (...) No caso de deficiente visual, também pra mim foi uma surpresa, né? (...)

F9: (...)Agora, o problema que eu sinto, assim, é quando é mental.

Os professores, que antes davam conta de suas aulas pelo conteúdo com o qual tinham sido formados, agora, têm "um certo receio... medo... pavor" de entrar em sala de aula e ter que "enfrentar" um aluno com NEE. Assim, ainda que não intencionalmente e mesmo sem consciência de que isso esteja acontecendo, os professores que trabalham no quadro de diversidade aqui discutido podem - pela apropriação de valores veiculados na escola desde sua formação - repetir ações que propiciam a exclusão. Acostumados à fragmentação curricular, geradora de aulas por conteúdo, que formam agentes mais afeitos a aceitar e repetir, os professores também sentem dificuldade de ser e de formar cidadãos críticos. Isso pode ser verificado nas atividades que me foram inicialmente enviadas por professores com os quais trabalho. Formados pelo conteúdo, mesmo pesquisando as dificuldades de um aluno com necessidades especiais, têm dificuldade de ver que o ensino pela repetição de estruturas abstratas (visão estruturalista de linguagem) não surtirá o efeito que eles buscam em suas salas de aula.

No exemplo abaixo, o aluno Miguel (nome fictício), é surdo profundo e, segundo a professora, se comunica por meio de LIBRAS. Ao analisarmos a redação, percebemos que o aluno utiliza preposições e artigos do português corretamente. Além disso, conjuga os verbos corretamente em português. Um dos estudos que venho realizando - e que espero ser foco de um projeto futuro - é uma comparação entre LIBRAS, que passei a estudar, e português e inglês, para saber como ensinar essa terceira língua aos surdos. Poucos surdos com quem eu tenha trabalhado, ou cujos textos eu tenha lido, mesmo dentre os mais bem sucedidos 
academicamente, utiliza as preposições, artigos e conjugações com a precisão desse aluno. Isso provavelmente se deve ao fato de LIBRAS, sua língua materna, não ter sinais para esse tipo de palavra gramatical. Por outro lado, o aluno tem erros como "merer" em vez de "mexer"; "istão" no lugar de "estão"; "patero" no lugar de "paterno". Ficam algumas perguntas: Teria o aluno, então, copiado a redação? - porque de outra forma seria difícil explicar a acuidade preposicional e de artigos, por exemplo. E qual ensino de língua inglesa teria ocorrido na elaboração dessa redação?

\section{Série $5^{\circ}$ ano \\ My family}

Eu moro com meu pai, minha mãe e meus irmãos na rua XXX em São Paulo.

Os meus avos istão, minha avo patero tem 78 anos de idade, minha avir materno tem 79 ano de idade, as duas moram em Minas Gerais. A avo paterno tem 20 filhos e a avo materno tem filhos e todo o ano [incompreensível].

Eu tenho 41 primos, eu gosto mais do meu primo Leonora mo e eu não gosto do meu primo Lucas porque ele gosta de merer nas meu nem coisas.

No exemplo a seguir, o aluno, diagnosticado como disléxico, copiou da lousa uma lista de vocábulos sobre família, com 27 itens. Considerando que algumas das características de alunos disléxicos são: (1) falta de memória para lembrar-se de coisas simples, como seu endereço, data de aniversário; (2) falta de concentração em sala de aula; (3) preferência por aulas de criatividade; (4) dificuldade para identificar letras em geral; (5) confusão ao ter que fazer ditados; (6) inversões, fica uma pergunta: como uma atividade de cópia lexical poderá auxiliar o aluno no ensino-aprendizagem de inglês? Algumas palavras sequer são compreensíveis mesmo em uma cópia. 


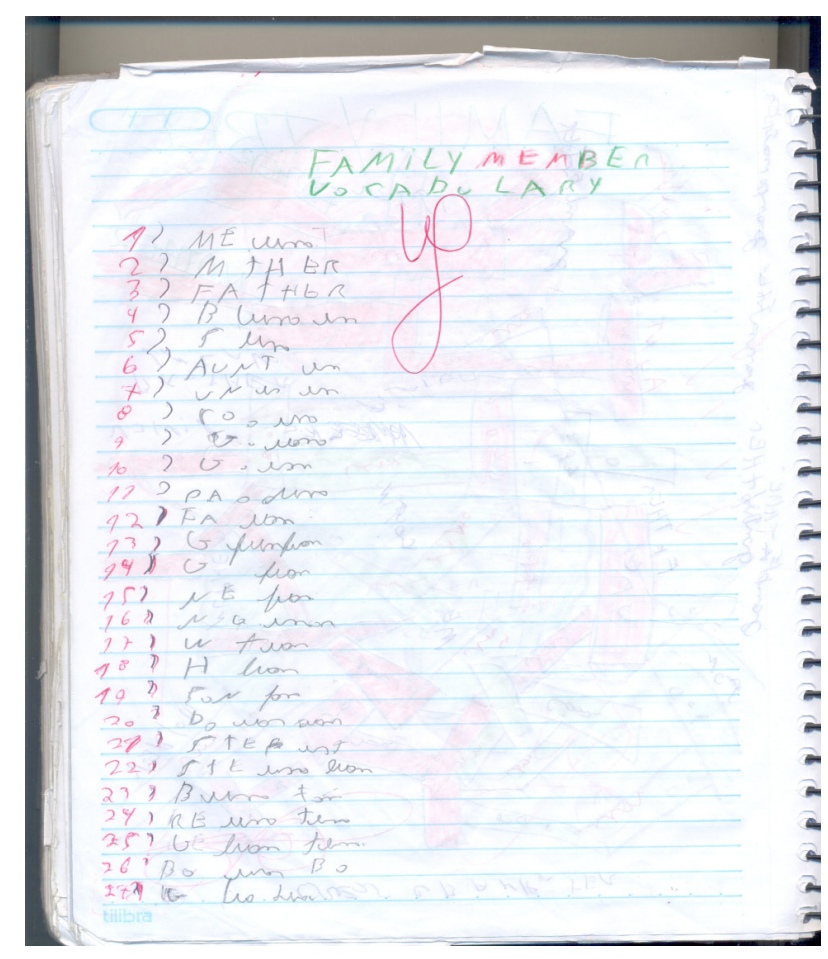

Os professores com os quais venho trabalhando me procuram porque não sabem o que fazer diante dos casos que têm em sala de aula, acostumados que estavam a receber alunos que ouvem, se comunicam, sabem organizar seu caderno, escrevem, separam as palavras etc. Os professores foram formados para o aluno que não apresenta problema sério de aprendizagem. A maioria dos professores sequer consegue identificar se o aluno tem dislexia - para poder encaminhá-lo a um profissional pedindo uma avaliação e diagnóstico, sem o qual, o aluno pode chegar ao final do ensino fundamental sem saber ler e sem ter recebido qualquer apoio porque ninguém na escola sabe o que fazer com ele. Os professores não foram formados para a diversidade que a escola apresenta hoje. E o que fazemos nós, na universidade diante dessa diversidade escolar? Quase nada, ainda.

No entanto, é importante lembrar que isso não faz bem nem aos professores que se sentem imobilizados, nem ao aluno que fica isolado em sala de aula. Os professores trazem traços claros de burnout, discutido por Codo (1999, p.254), como 
Muitos professores estão exatamente assim: presos a uma situação de trabalho da qual gostariam de se desvencilhar e sem condições de executá-la como sabem que deveriam; ou como gostariam. 0 magistério, como profissão, apresenta traços visíveis de um efeito de burnout coletivo: uma profissão desvalorizada; com pouca procura nos cursos universitários por cursos de licenciatura. Teimo em repetir: e o que fazemos nós, na universidade diante dessa diversidade escolar? Quase nada, ainda.

\section{REFERÊNCIAS}

ALENCAR, Chico. Educação no Brasil: um breve olhar sobre nosso lugar. In: GENTILI, Pablo; ALENCAR, Chico. Educar na esperança em tempos de desencanto. Petrópolis: Vozes, $3^{a}$ edição, 2001, p.45-64

BAKHTIN, Mikhail/ Volochínov, V. N. Marxismo e filosofia da linguagem. São Paulo: Hucitec, $9^{a}$ edição, 1929/1999.

BAUMAN, Zygmunt. Ética pós-moderna. São Paulo: Paulus, 1997.

BISSERET, Nòelie. A ideologia das aptidões naturais. In: DURAND, José Carlos Garcia. (org.). Educação e hegemonia de classe: as funções ideológicas da escola. Rio de Janeiro: Jorge Zahar Editor, 1978, p. 30-67.

BRASIL, MEC. Lei de Diretrizes e Bases 9394. Brasília: MEC. 1996. Acessado em: portal.mec.gov.br/arquivos/pdf/ldb.pdf

BRASIL. Constituição da República dos Estados Unidos do Brasil (de 16 de Julho de 1934). Brasília. Presidência da República; Casa Civil. 1934. Acessado em: http://www. planalto.gov.br/ccivil_03/Constituicao/Constituica034.htm

BRASIL. Constituição dos Estados Unidos do Brasil (de 10 de Novembro de 1937). Brasília: Presidência da República; Casa Civil. 1937. Acessado em: http://www.planalto.gov.br/ ccivil_03/constituicao/constitui\%C3\%A7a037.htm

BRASIL, Decreto $n^{0} 60.501$ - de 14 de março de 1967. Brasília: Presidência da República. Acessado em: http://www010.dataprev.gov.br/sislex/ paginas/23/1967/60501.htm. 
BRASIL, MEC; Lei de Diretrizes e Base 4024/61. Brasília: MEC. 1961. Acessado em: http://www.jusbrasil.com.br/ legislacao/129047/lei-de-diretrizes-e-base-de-1961lei-4024-61

BRASIL. Casa Civil; Subchefia para Assuntos Jurídicos. Constituição da República Federativa do Brasil de 1967. Acessado em http://www.planalto.gov.br/ccivil_03/ constituicao/constituicao67.htm

BRASIL; Câmara dos Deputados; Projeto de Lei Carlos Lacerda. 1955. http://www.camara.gov.br/internet/sileg/ Prop_lista.asp? Pagina $=2 \&$ Autor $=400027 \&$ Limite $=\mathrm{N}$

BRONCKART, Jean-Paulo; MACHADO, Anna Rachel. Procedimentos de análise de textos sobre o trabalho educacional. In MACHADO, Anna Rachel (org). O ensino como trabalho: uma abordagem discursiva. Londrina: Eduel e Fapesp, $1^{\mathrm{a}}$ edição, 2004, p. 131-166.

CODO, Wanderley. Educação, carinho e trabalho. Petrópolis, RJ: Vozes / Brasília: Universidade de Brasília. Laboratório de Psicologia do Trabalho, 1999.

DOMINGUES, Octávio. A hereditariedade em face da educação. São Paulo: Companhia Melhoramentos, 1929.

FOUCAULT, Michel. A ordem do discurso. São Paulo: Loyola, $9^{a}$ edição, 1970/2005.

FREIRE, Paulo. Pedagogia do oprimido. Rio de Janeiro: Paz e Terra, $28^{a}$ edição, 1970/2000.

FREIRE, Paulo. Pedagogia da autonomia. Rio de Janeiro: Paz e Terra, 1996.

GENTILI, Pablo. Escola e cidadania em uma era de desencanto. In: SILVA, Shirley; VIZIM, Marli. (Org's). Educação especial: múltiplas leituras e diferentes significados. Campinas: Mercado de Letras, 2001, p. 41-55.

HABERMAS, Jürgen. O futuro da natureza humana. São Paulo: Martins Fontes, 2004.

KINCHELOE, Joe L. A formação do professor como compromisso político: mapeando o pós-moderno. Porto Alegre: Artmed, 1993/1997. 
LEONTIEV, Alexis. Activity and Consciousness. In: Philosophy in the USSR: Problems of Dialectical Materialism. Progress Publishers. Disponível em <http://www.marxists.org/portugues/leontiev/1978/ actividadeaoncienciaepersonalidade// introducao.htm, 1978/1997>. Acesso em 11 jun. 2003.

LIBERALI, Fernanda Coelho. Cadeia criativa: uma possibilidade para a formação crítica na perspectiva da teoria da atividade sócio-histórico-cultural. In MAGALHÃES, Maria Cecília Camargo; FIDALGO, Sueli Salles (Orgs). Questões de método e de linguagem na formação docente. Campinas: Mercado de Letras, 2011, p.41-64.

MAGALHÃES, Maria Cecília Camargo; FIDALGO, Sueli Salles. Critical collaborative research: focus on the meaning of collaboration and on mediational tools. Revista Brasileira de Linguística Aplicada, Belo Horizonte, UFMG, v.10, n.3, p. 773 797, 2010.

MAGALHÃES, Maria Cecília Camargo; FIDALGO, Sueli Salles. Teacher education language in collaborative and critical reflective contexts. In. GIL, Gloria; VIEIRA-ABRAHÃO, Maria Helena (Org.). Educação de professores de línguas: os desafios do formador. Campinas: Pontes, 2008, p. 105-126.

MAGAlHÃES, Maria Cecília Camargo. Pesquisa Crítica de Colaboração: escolhas epistemo-metodológicas na organização e condução de pesquisas de intervenção no contexto escolar. In: MAGALHÃES, Maria Cecília Camargo; FIDALGO, Sueli Salles (Orgs). Questões de método e de linguagem na formação docente. Campinas: Mercado de Letras, 2011, p. 13-40.

MAGALHAES, Maria Cecília Camargo. A Pesquisa Colaborativa e a Formação do Professor Alfabetizador. In: FIDALGO, Sueli Salles; SHIMOURA, Alzira da Silva (Orgss). Pesquisa crítica de colaboração um percurso na formação docente. São Paulo: Ductor, 2007, p. 48-55.

MAZZOTTA, Marcos José Silveira. Educação especial no Brasil: história e políticas públicas. São Paulo: Cortez, 1995.

MIGNOLO, Walter D. Histórias locais/Projetos globais: colonialidade, saberes subalternos e pensamento liminar. Belo Horizonte: UFMG, 2003. 
PATTO, Maria Helena Souza. A produção do fracasso escolar: histórias de submissão e rebeldia. São Paulo: Casa do Psicólogo, 1999.

SASSAKI, Romeu Kazumi. Como chamar as pessoas que têm deficiência. São Paulo: RNR, 2003.

SAVIANI, Demerval. A nova lei da educação: LDB trajetória, limites e perspectivas. São Paulo: Editora Autores Associados, 1997.

SCHWARCZ, Lilia Moritz. O espetáculo das raças: cientistas, instituições e questão racial no Brasil 1870-1930. São Paulo: Cia. das Letras, 1993.

VYGOTSKY, Lev Semenovich. Pensamento e linguagem. São Paulo: Martins Fontes, 1930/1999.

VYGOTSKY, Lev Semenovich. A formação social da mente. São Paulo: Martins Fontes, 1934/2007.

Recebido em fevereiro de 2012 Aprovado em março de 2012 